W. PSCHYREMBEL

\title{
KLINISCHES WÖRTERBUCH
}





\title{
K L I N I S C H E S
}

\section{W Ö R T E R B U C H}

VON

\section{WILLIBALD PSCHYREMBEL}

DR. MED. DR. PHIL.

OBERARZT AM STÄDTISCHEN KRANKENHAUS BERLIN-NEUKÖLLN

\author{
GEGRUNDET VON \\ OTTO DORNBLUUTH
}

54. BIS 60. AUFLAGE

MIT 632 ABBILDUNGEN IM TEXT

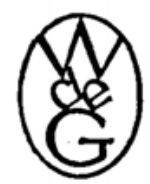

I $\quad 9 \quad 4 \quad 3$

WALTER DE GRUYTER \& CO. / BERLIN

vormals G. J. Goschen'sche Verlagshandlung/J. Guttentag, Verlagsbuchhandlung Georg Reimer/Karl J. Trubner / Veit \& Comp. 
Alle Rechte, insbesondere das der Utbersetzung, vorbehalten Copyright 1943 by WaLter DE GRUYTer \& Co. vormals G. J. Gőschen'sche Verlagghandlung - J. Guttentag, Verlagsbuchhandlung - Georg Reimer - Karl J. Trübner - Veit \& Comp. Berlin W 35, Woyrschstraße 13

Arohiv-Nr. 510143

Printed in Germany

DRUCK VON METZGRR\& WITTIG IN LEIPZIG 